Article

\title{
Low Impact Development Design—Integrating Suitability Analysis and Site Planning for Reduction of Post-Development Stormwater Quantity
}

\section{Xinhao Wang ${ }^{1} *$, William Shuster ${ }^{2}$, Chandrima Pal ${ }^{1}$, Steven Buchberger ${ }^{3}$, James Bonta ${ }^{4}$ and Kiran Avadhanula ${ }^{1}$}

1 School of Planning, College of Design, Architecture, Art, and Planning, University of Cincinnati, Cincinnati, OH 45221-0016, USA; E-Mails: palc@email.uc.edu (C.P.); vadhakk@email.uc.edu (K.A.)

2 Sustainable Environments Branch, National Risk Management Research Laboratory, Office of Research and Development, United States Environmental Protection Agency, 26 W. Martin Luther King Drive, Cincinnati, OH 45268, USA; E-Mail: shuster.william@epa.gov (W.S.)

3 Department of Civil and Environmental Engineering, College of Engineering, University of Cincinnati, Cincinnati, OH 45221-0071, USA; E-Mail: steven.buchberger@ ucmail.uc.edu (S.B.)

4 North Appalachian Experimental Watershed, Agricultural Research Service, United States Department of Agriculture, Coshocton, OH 43812, USA; E-Mail: jim.bonta@ars.usda.gov (J.B.)

* Author to whom correspondence should be addressed; E-Mail: xinhao.wang@ucmail.uc.edu; Tel.: +1-513-556-4943; Fax: +1-513-556-1274.

Received: 29 June 2010; in revised form: 14 July 2010 / Accepted: 30 July 2010 / Published: 3 August 2010

\begin{abstract}
A land-suitability analysis (LSA) was integrated with open-space conservation principles, based on watershed physiographic and soil characteristics, to derive a low-impact development (LID) residential plan for a three hectare site in Coshocton $\mathrm{OH}$, USA. The curve number method was used to estimate total runoff depths expected from different frequency storms for: (i) the pre-development condition, (ii) a conventional design, (iii) LID design based on the LSA of same building size; and (iv) LID design based on the LSA with reduced building footprints. Post-development runoff depths for the conventional design increased by 55 percent over those for the pre-development condition. Runoff depth for the same building size LSA-LID design was only 26 percent greater than that for the pre-development condition, and $17 \%$ for the design with reduced building sizes. Results suggest that prudent use of LSA may improve prospects and functionality
\end{abstract}


of low-impact development, reduce stormwater flooding volumes and, hence, lower site-development costs.

Keywords: soil survey; runoff; soil hydrologic group; urbanization; suitability analysis

\section{Introduction}

Because post-development hydrology is important to developers and municipalities that must comply with the USEPA National Pollution Discharge Elimination System Phase II regulations, a simple method is needed during planning to guide the placement of impervious surfaces on a landscape. To maximize the opportunities for economical low impact on hydrology and water quality, the method must consider the unique spatial distribution of physical, topographical, and climatological features of the watershed. The objective of the present study is to develop and test a simple, objectively-applied, method that integrates land suitability analysis (LSA) that incorporates landscape features, soils, and climatological data and Low Impact Development (LID) to aid in reducing the anticipated increase in stormwater runoff flood volumes from a residential development.

A land suitability analysis (LSA) considers relevant factors to identify proper locations for different land uses. Land suitability analysis is a systematic procedure for examining the combined effects of a related set of factors that the analyst assumes to be important determinants of locational suitability [1]. The meaning of suitability is to prioritize areas in terms of supporting proposed land use, considering social, physical, spatial or economic factors. The most suitable land will be used for development first.

The foundational work of McHarg (1969) popularized overlays of natural resources and landscape physiography to analyze land-suitability for, and impacts of, development plans [2]. Furthermore, land-use planning decisions that encompass wildlife habitat, aesthetic and recreational aspects, and demand for open space have recently been joined by the imperative of stormwater-runoff management [3]. These various planning and development themes are consistent with concepts of decentralized stormwater management infrastructure and runoff-source control, which attempt to maximize precipitation losses in the hydrological cycle (infiltration, evapotranspiration, interception, abstraction, and ground-water recharge) and minimize surface runoff. The philosophy and approach to decentralization and source control are brought together under green infrastructure (GI) [4,5]. One tenant of GI is to reconnect fragmented areas that have the potential to reduce high rates and volumes of runoff during storms. The end result of GI techniques yields contiguous corridors and areas of vegetated landscape that are proximate to areas of development. Several researchers have suggested that land is more likely to be managed in a near-natural state if it satisfies multiple objectives including stormwater management $[3,6]$.

LID applies principles of green infrastructure to bring together site-planning and stormwater-management objectives [7-10]. The LID philosophy can be used to retrofit existing development and to plan new sites. Examples of this planning approach have been successfully implemented in municipalities throughout New England and the Mid-Atlantic states in the United States [11,12]. Some facets of LID include: (a) integrating conservation goals of wetlands protection, habitat preservation, or aesthetic requirements into the design; (b) minimizing development impacts on 
sensitive landscape locations (e.g., soils and landscapes prone to erosion) or preserving unique landscape characteristics (e.g., soils with high infiltration rates and good drainage, stands of mature vegetation) by using site-specific data in subsequent engineering design ; (c) maintaining natural or pre-development timing of peak-water flows through the watershed; (d) implementing multifunctional, small scale, source-control stormwater management practices that can be integrated directly into existing stormwater infrastructure and landscape; and (e) reducing or eliminating pollution at its source, instead of allowing it to be conveyed downstream.

Soils and topography play a significant role in minimizing stormwater runoff because these attributes vary considerably across even small landscapes, affecting infiltration, runoff, and drainage patterns. Although the spatial distribution of soils and their properties are usually considered in the planning process, the level of detail is often limited to a coarse county-level soil survey (e.g., STATSGO2 database developed by the USDA-Natural Resources Conservation Service in the USA) [13]. The spatial resolution of these soils data are often not sufficient for designing stormwater management practices that rely on infiltration processes.

Soil maps ("order-1 surveys") with much better spatial resolution than county-level maps, are often prepared for detailed studies on small tracts of land [14]. The more detailed order-1 survey provides better spatial resolution, and offers more opportunities to the designer for identifying areas where development should be avoided for small development features (e.g., houses, driveways, and streets) in order to minimize runoff potential of a proposed integrated pervious-impervious landscape drainage system.

Although many rainfall-runoff models are in current use, hydrological models that incorporate the NRCS curve number method are useful to anticipate and compare runoff quantities from different land uses [15]. The curve-number is a rainfall-runoff model that lumps site characteristics (hydrologic soil group, land use, vegetative cover) into a quantity known as a "curve number" (CN). A CN represents the runoff potential of a watershed, with values ranging between 0 and 100 (larger CNs represent watersheds with high runoff potential such as a rooftop) [16]. The $\mathrm{CN}$ method is incorporated into many models widely used today at the large and small spatial scales to estimate the total runoff volume from watersheds, and in subsequent methods to estimate peak runoff rates for storms of varying frequencies [17-21]. The $\mathrm{CN}$ method applied to a watershed utilizes the spatial delineation of soil map units, land use, and vegetative cover to compute an area-weighted average watershed $\mathrm{CN}$ to estimate runoff volumes.

The present study only focuses on the development and testing of a proof of the concept. Project economics are not considered. Total runoff depths expected from different frequency storms for four scenarios are compared: (i) the pre-development condition, (ii) a conventional design, (iii) LID design based on the LSA of same building size of the conventional design; and (iv) LID design based on the LSA with reduced building footprints.

\section{Experimental Section}

\subsection{Study Site Characterization}

The 3-hectare experimental watershed used in this study (WS185) is located at the watershed facility operated by the USDA-Agricultural Research Service-North Appalachian Experimental 
Watershed (NAEW) near Coshocton, Ohio in the USA (Figure 1). The climate is a continental pattern and receives an annual average of approximately $1,000 \mathrm{~cm}$ of precipitation. The greatest amount of precipitation normally occurs from May through August, a period when vegetative cover would be well-developed [22]. The predominant land use at the site is hay meadow from 1986 to the present time.

Figure 1. Topography of Watershed 185 at the NAEW near Coshocton, Ohio, USA.

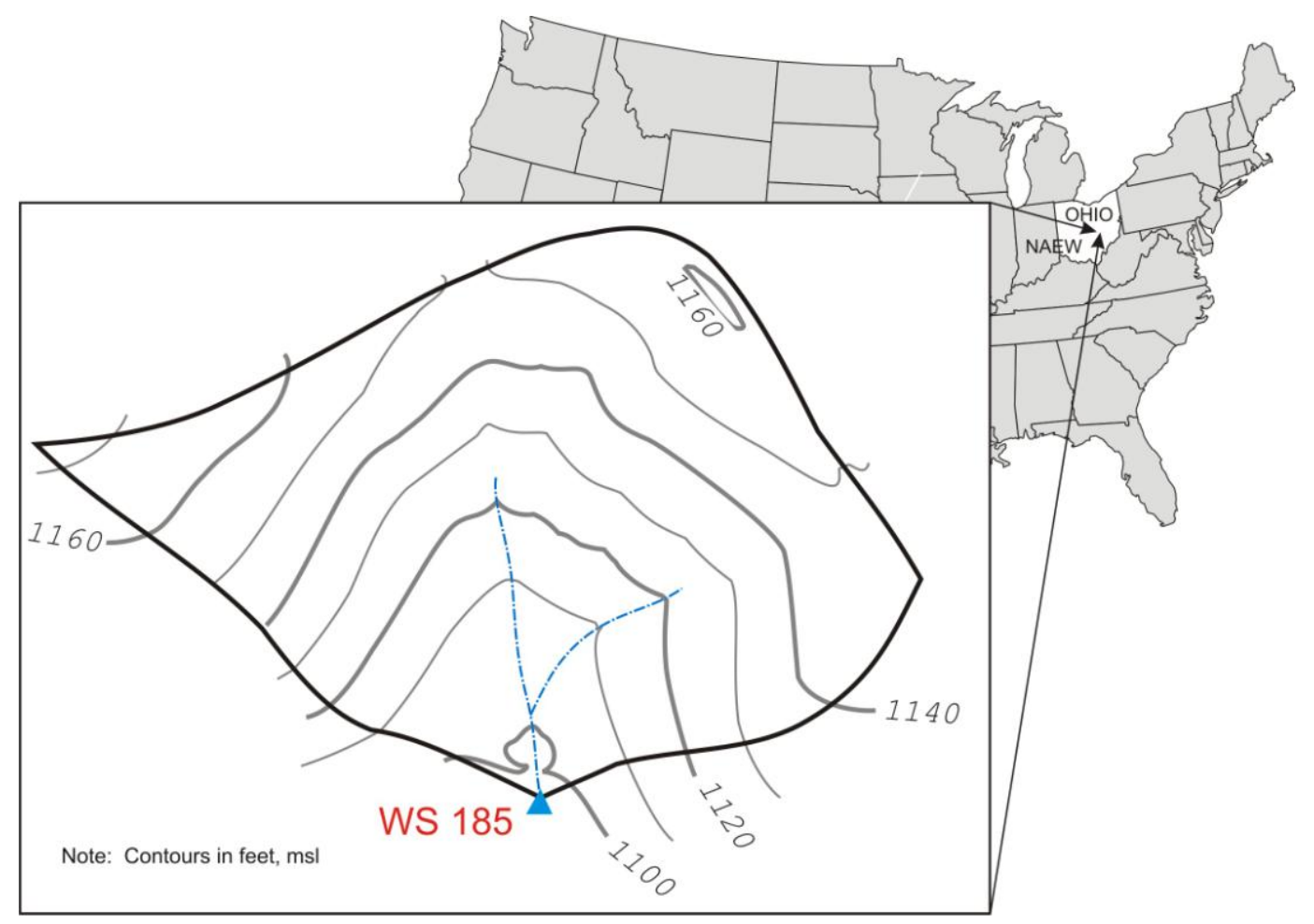

Data used in the study include order-1 soil survey data and a topographic map developed using 4-ft contours. An order-1 soil survey of WS185 was prepared by the USDA-Natural Resources Conservation Service (NRCS) in 2002. To prepare an order-1 soil survey map, the landscape is first visually divided into areas based on slope and landscape position. Survey map-unit boundaries are then estimated on the basis of known soil series in the area. Soil samples are obtained for each soil map unit to confirm and refine the initial classification of soil series and obtain better resolution of soil boundaries. Information gained from field-sampled soils include evidence of redoximorphic horizons (drainage tendency), argillic zones (long-term leaching behavior), texture (spatial variability in hydraulic conductivity at scales $<1 \mathrm{~m}$ ), soil depth (potential for drainage), bedrock geology (potential for deep percolation) to qualitatively characterize infiltration and drainage properties.

Files for soil mapping polygons, local roads, and topography were overlaid using ArcGIS 9.3 (ESRI International; Redlands CA). Information from the soil survey was used to determine one of four NRCS hydrologic soil groups (HSG) for each map unit required by the $\mathrm{CN}$ method to quantify infiltration characteristics. The four HSG categories are A, B, C or D, in a sequence from higher to lower infiltration potential. The drainage characteristics of the soil map units were classified from the soil survey as well drained, moderately well drained, and well drained with localized spots of wetter soils (Figure 2). The 4-foot elevation contours were used to create a land surface slope layer measured 
as percent slope. The percent slope was further reclassified into 5 classes from a flat area to most steep slope area (Figure 3).

Figure 2. NRCS hydrologic soil groups and drainage categories for Watershed 185 at the NAEW.

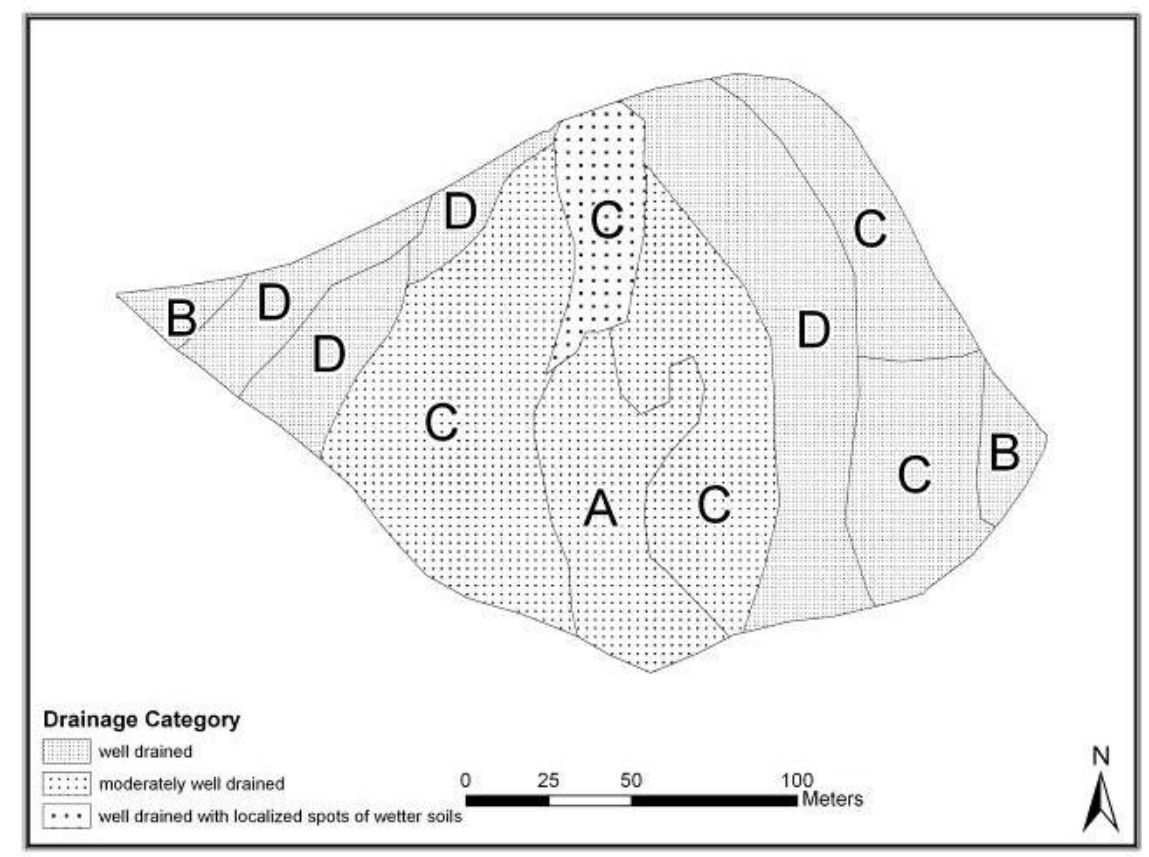

Figure 3. Slope categories of Watershed 185 at the NAEW.

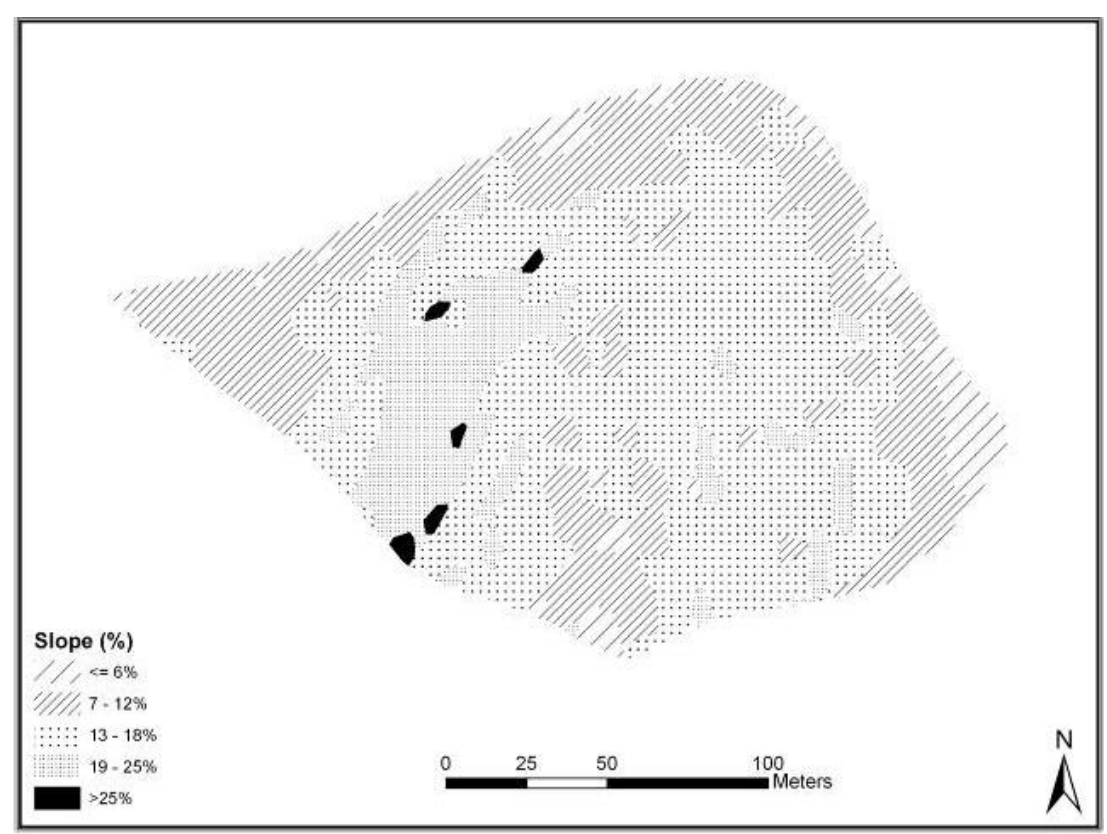

\subsection{Land Suitability Analysis}

Land suitability analysis was used to determine the degree of suitability, based on factors deemed important, for proposed land use (Table 1) [3,23]. Factors selected for the suitability analysis in this study were slope, hydrologic soil group (HSG), and soil drainage classification (Table 1). Overlaying those factors generated many small polygons throughout the watershed. Each of the polygons was 
calculated a suitability score. The spatial variation of those values provided the basis for guiding land development.

Each factor was scored on a scale from 0 to 10, with a maximum score of 10 representing the most suitable and 0 , the least suitable for the proposed residential development. The slope factor score was maximized for areas with the flattest slopes. Development on soils belonging to HSG A (i.e., soils with low runoff potential) is discouraged, as permeability is relatively high, and, hence these soil units would be expected to mitigate runoff. On the other hand, pre-development soils belonging to HSG groups $\mathrm{C}$ and $\mathrm{D}$ have lower permeability and their runoff potential is relatively larger, approaching that found for impervious areas. Therefore, larger scores are given to encourage development in these areas. Finally, drainage capability quantifies how well overland runoff is drained from the property through the soil horizon, and high scoring was assigned well-drained areas to encourage development on areas with high potential of runoff.

Table 1. Suitability factor scores.

\begin{tabular}{|c|c|c|c|c|c|}
\hline \multicolumn{2}{|c|}{ HSG $(\mathrm{Wt}=7)$} & \multicolumn{2}{|c|}{ Slope $(\mathbf{W t}=10)$} & \multicolumn{2}{|l|}{ Drainage $(\mathrm{Wt}=5)$} \\
\hline Category & Value & Category & Value & Category & Value \\
\hline $\mathrm{A}$ & 1 & $<=6 \%$ & 10 & Well-drained & 10 \\
\hline B & 4 & $7-12 \%$ & 7 & Moderately well-drained & 6 \\
\hline $\mathrm{C}$ & 7 & $13-18 \%$ & 4 & Well drained with localized spots of wetter soils & 7 \\
\hline $\mathrm{D}$ & 10 & $19-25 \%$ & 1 & - & - \\
\hline- & - & $>25 \%$ & 0 & - & - \\
\hline
\end{tabular}

Scores were then weighted to reflect their relative importance in determining the suitability of development activity in a given area of the watershed. In the absence of criteria to rate the importance of each factor, heuristic arguments were applied to weight these factors. Slope was assigned a weight of 10 as it affects construction practices and therefore may be a more meaningful factor to developers. Slope also influences the potential for infiltration and peak runoff rate along the landscape, and therefore higher slopes would limit infiltration and increase runoff peak flows perpendicular to landscape contours. The HSG was given a weight of 7 due to its effects on infiltration potential which was considered a serious imposition on the prospects for development. Runoff control has not been typically accounted for in development plans, and therefore not a high priority for consideration by developers. The drainage factor was given the lowest weight of 5.

Suitability analysis was conducted with Scenario 360 software (Placeways, Boulder, CO) which was implemented on ArcGIS (Ver. 9.3; ESRI Inc., Redlands CA). This software facilitated the calculation of a suitability score from geospatial data (slope, HSG, drainage scores and weights), which were attributed to each soil-survey map unit. The suitability score (SS) was a simple weighted sum calculated with a matrix method as:

$$
S S=\sum_{i}\left(W_{i} \bullet s_{i}\right) / \sum i
$$

where $\mathrm{W}$ and $\mathrm{s}$ are the weight and the attribute score for factor i, respectively. A higher suitability score suggests an area appropriate for development, and areas with lower scores should be conserved for infiltration and to maintain pervious areas to minimize runoff generation. 


\subsection{Development Plans}

Because there were only a few spots where slope exceeded $25 \%$, there were no restrictions on the conventional development and the layout of lots was based upon De Chiara et al. and suburban development guidelines published for Wayne and Coshocton counties, $\mathrm{OH}$ [24]. It has a checkerboard layout of large lots accessed by a wide street ending in a cul-de-sac. The typical cul-de-sac radii recommended by most city ordinances are equal or greater than 15 meters.

Guidelines for open space conservation design principles were adapted from Arendt $(1996,1999)$ to create LID plans [11,25]. The features of the design which distinguishes it from a conventional design are:

Narrower Streets: The American Society of Civil Engineers, in cooperation with the National Association of Home Builders and the Urban Land Institute, suggests street design to be based on the logical premise that street should be appropriate to its functions [25]. Streets with 5.5-6 meters (18-20 feet) of paved width is enough for roads serving rural subdivisions with few homes [11].

Smaller and compact lots: The lot sizes are reduced to that they fit inside the zone designated for building construction. Reducing lot size helps in preserving open space for common use, produces compact neighborhoods where neighbors can see and talk to each other more easily and more often.

Alternative to cul-de-sac: Instead of cul-de-sac design (as used in conventional design) which converts a large amount of space to impervious surface, alternate designs are often used. For example, the LID design for this study uses a simple "hammerhead "or "Turning T" to serve the five houses, as illustrated by [11].

Reducing front setbacks: Because lots are smaller in size, front setbacks are reduced and houses can be closer to the access road. This helps to decrease length of driveway and increase backyard space. Reducing front yard length does not diminish the quality of design because backyards are used more often for family recreation than front yards, and hence need to be bigger.

Bike trail /walk trail: Many people do in fact take advantage of opportunities to walk around the neighborhood when that choice exists [26]. Hence, a walking/bilking trail is designed to link houses with the common space and to the access road. The trail can be enjoyed by everybody for a pleasant morning or evening walk around the neighborhood.

Common space: A part of the common space where the slopes are relatively flatter, is designed as a small picnic ground/park accessible from the homes via the walking/biking trail. This space can be used to organize activities or for just casual sitting and games.

\subsection{Curve-Number Application}

The NRCS curve-number method $(\mathrm{CN})$ converts rainfall to runoff as a function of soil hydrologic group and land cover-type condition (Table 2) [15]. The pre-development land cover was assumed as "pasture in good hydrologic condition". The pervious areas under the developed scenarios were treated as "grass cover greater than 50\% and less than 75\%". Impervious surfaces (e.g., roads, roof tops, and driveways) were assigned a $\mathrm{CN}$ of 98. 
Table 2. Watershed curve numbers.

\begin{tabular}{c|c|c|c|c|c}
\hline Land Cover & NRCS Cover Type and Hydrologic Condition [15] & A & B & C & D \\
\hline Pre-development & Pasture Grassland or Range in good hydrologic condition & 39 & 61 & 74 & 80 \\
\hline $\begin{array}{c}\text { Pervious area of the } \\
\text { development scenarios }\end{array}$ & Grass cover greater than 50\% and less than 75\% & 49 & 69 & 79 & 84 \\
\hline Roof tops and driveways & Paved parking lots, roofs, driveways, etc. & 98 & 98 & 98 & 98 \\
\hline Streets & Streets and roads: paved; curbs and storm drains & 98 & 98 & 98 & 98 \\
\hline
\end{tabular}

Curve numbers from each land unit are then area-weighted to yield a composite curve number. 24 hour rainfall depths $(\mathrm{P})$ corresponding to different recurrence intervals ranging from 2 to 25 years were used to generate runoff depth through the $\mathrm{CN}$ method. Briefly, runoff depth $(\mathrm{Q})$ is computed using the CN Equation [16]:

$$
Q=\frac{(P-0.2 S)^{2}}{(P+0.8 S)}
$$

where $\mathrm{S}$ is the depth of potential maximum watershed retention of rainfall after the initiation of storm runoff. The relationship between $\mathrm{S}$ and $\mathrm{CN}$ was developed in the $\mathrm{CN}$ method as a convenience so that $\mathrm{CN}$ would range from 0 to 100 to correspond with larger $\mathrm{CN}$ for larger runoff potential:

$$
S=(1000 / C N)-10
$$

The values for assigned $S$ are then substituted into Equation 2 to yield a runoff depth. Equations 2 and 3 require that $\mathrm{Q}, \mathrm{P}$, and $\mathrm{S}$ have units of inches, but $\mathrm{Q}$ and $\mathrm{P}$ are afterwards converted to $\mathrm{cm}$.

As is often assumed in hydrology, the runoff-depth frequency curve was assumed equal to that of rainfall depth. The magnitudes and frequencies of 24 hour rainfall used in Equation 2 were obtained from Huff and Angel and used in Equation 2 [27]. Development designs for undeveloped, conventional development, and two LSA-LID scenarios were compared by using the runoff depths computed from Equation 2 for different precipitation frequencies.

\section{Results and Discussion}

\subsection{Land Suitability Scores}

The goal of the land suitability analysis was to find those areas which would both accommodate development with the smallest increase in runoff from the watershed (Figure 4). The low areas near the outlet of the watershed represent soils with highest permeability (Figure 2). The majority of runoff that is generated from the upslope areas is infiltrated at this central area in the toe slope of the watershed, which is underlain by a moderately-drained, relatively permeable formation of Oxyaquic Udifluvent soil located slightly upstream from the outlet. The high capacity for infiltrating and detaining runoff has led to historically small amounts of flow measured at the outlet flume, based on over 40 years of data collection [22]. Priority for conservation of these areas was borne out by the results of the suitability analysis, which relied on good detail in spatial delineation of soils and their hydrologic properties from the order-1 survey. The use of this detailed soils data stands in contrast to using 
commonly-available soils survey data [28], which indicated Coshocton silt-loam soils with moderate slope in the mid- and toe-slope areas, with the ridge top composed of Gilpin silt-loam soil. HSG group $\mathrm{C}$ is assigned to both soil types, and are generally moderately well-drained with areas of poorer drainage due to shallow soil depth or nearby clay lenses. It stands to reason that the use of coarser resolution data from the county survey would have entirely missed the soil features of the watershed that were appropriate for identifying runoff management opportunities, and therefore a suitability analysis incorporating this coarse spatial resolution of soil characteristics was not performed.

Figure 4. Land suitability scores on Watershed 185 at the NAEW.

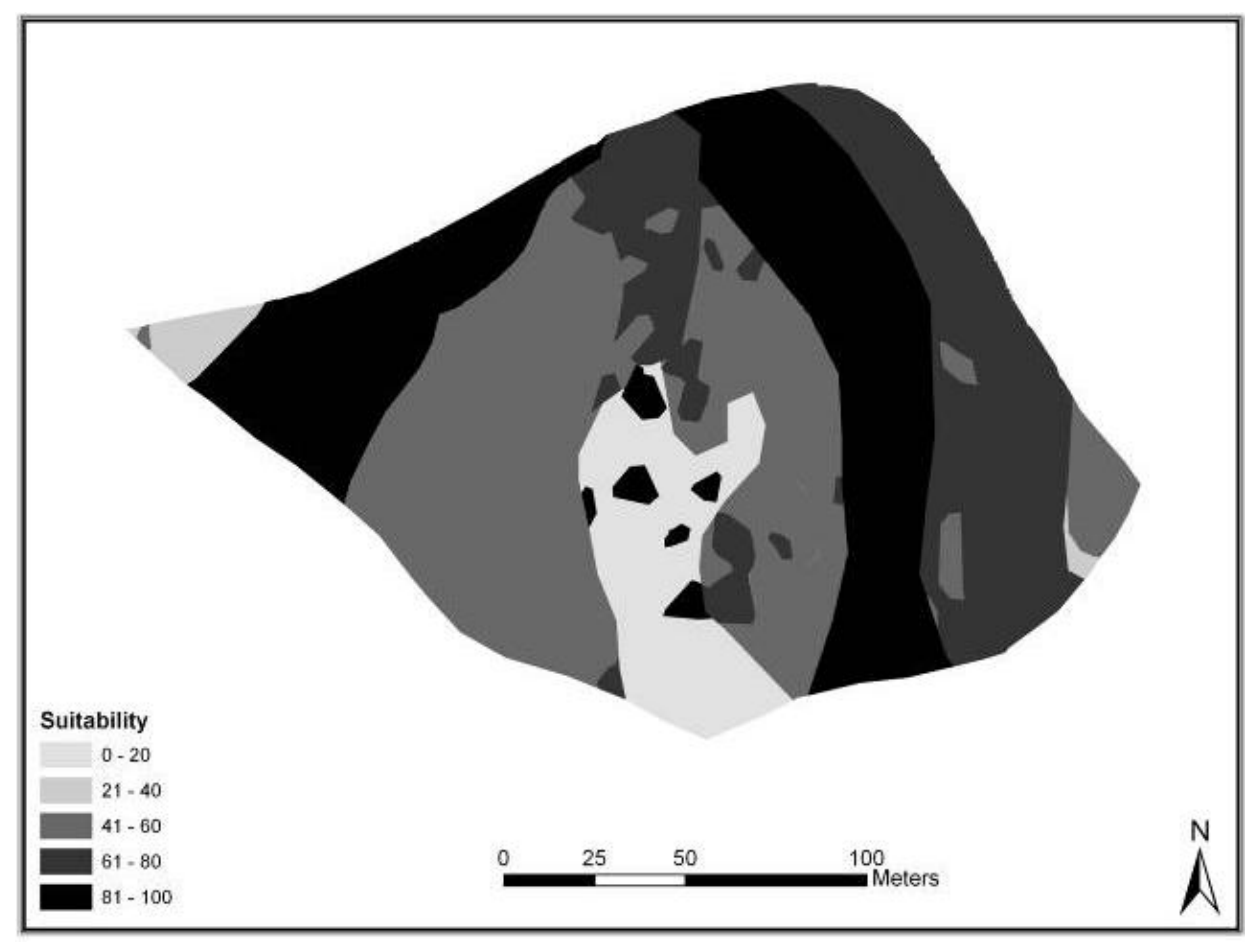

\subsection{Development Design Scenarios}

According to conventional subdivision design, the only restrictions that may make some of the land within a parcel to be "legally unfit for building" are those which have very steep slopes, contain wetland or are inside the floodplain. Flood plain and wetland restrictions do not apply to the study site and hence for this scenario the assumption is made that the developer designs the subdivision according to conventional large lot subdivision regulations using the entire site except areas with slope greater than $25 \%$. Figure 5 shows the design in accordance with most conventional subdivisions. Five $255-\mathrm{m}^{2}$ dwellings set upon lots between 0.46 and 0.60 ha in size. The lots are arranged in a circular pattern about an 18-m diameter cul-de-sac. The driveway width is approximately 6-7 $\mathrm{m}$ and the access road is $15 \mathrm{~m}$ wide. 
Figure 5. Conventional site plan on Watershed 185 at the NAEW.

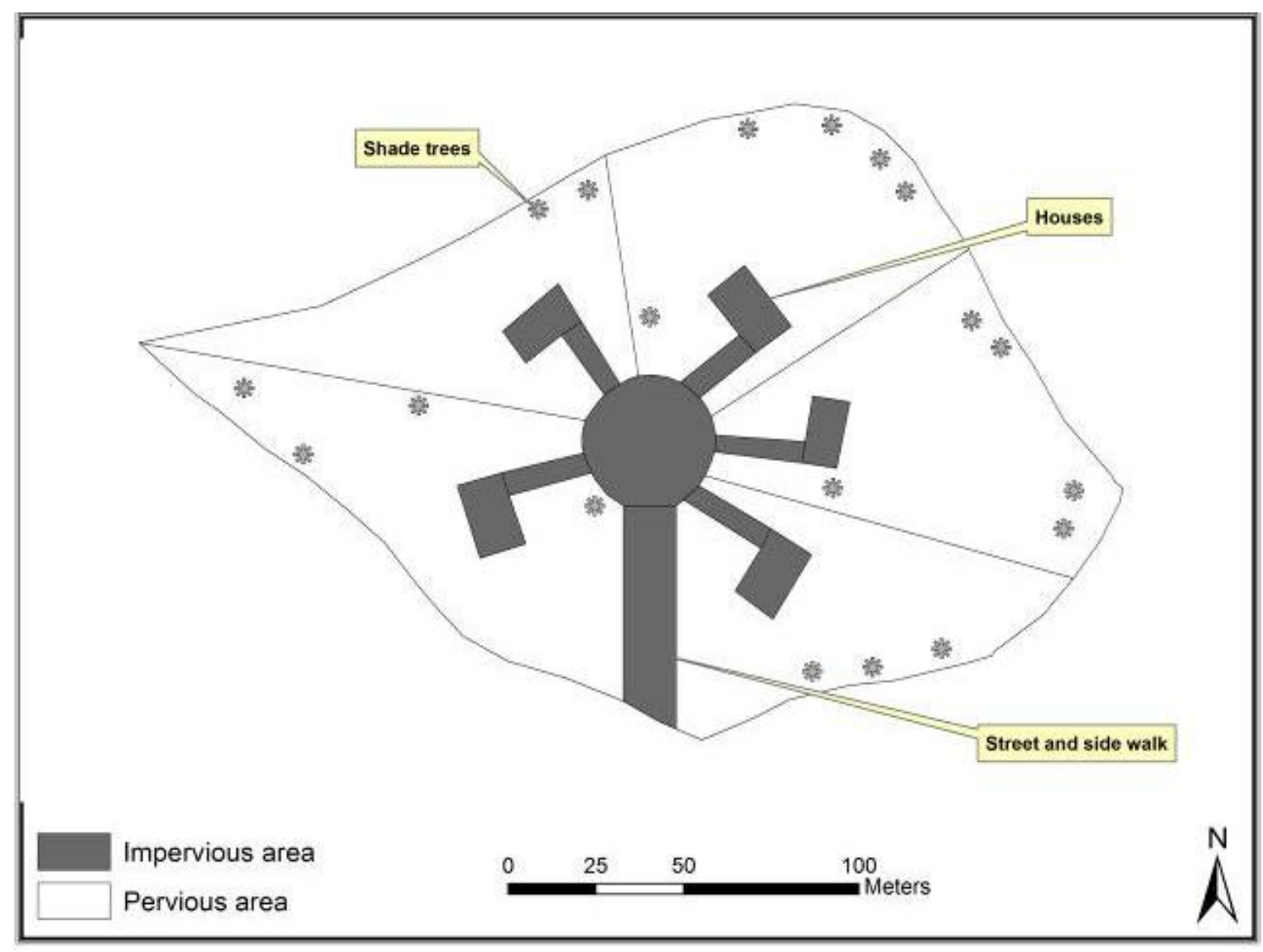

Two LSA-LID plan scenarios were developed based on the land suitability analysis (Figures 6 and 7). In the first LSA-LID scenario (Figure 6), the building areas are sized similar to the conventional plan. In the second LSA-LID scenario (Figure 7), each residential dwelling area is reduced to $140 \mathrm{~m}^{2}$. House lots were decreased in area for the LSA-LID scenarios ( 0.063 ha to $\left.0.086 \mathrm{ha}\right)$ as it was assumed that the decreased house lot area in the LSA-LID plans would be compensated for by natural greenways and open spaces in the surrounding neighborhood compared with the conventional development plan [29]. Larger open spaces serve multiple purposes and may therefore be more valuable to the inhabitants of this development [3].

The American Society of Civil Engineers, in cooperation with the National Association of Home Builders and the Urban Land Institute, suggests street design to be based on the premise that the design of a residential street should match its function [25]. For example, a 6-m paved width is thought to be sufficient for roads serving rural subdivisions with few homes [11]. Accordingly, a maximum road width of $6 \mathrm{~m}$ was implemented in the LSA-LID scenarios (compared with 15-m for conventional) to provide access to the five houses. Furthermore, instead of a cul-de-sac design (as used in the conventional design), which converts a large proportional amount of open space to impervious area, a simple "hammerhead "or "Turning T" design was used in the LSA-LID plans. 
Figure 6. LSA-LID site plan 1 on Watershed 185 at the NAEW (same building size as conventional).

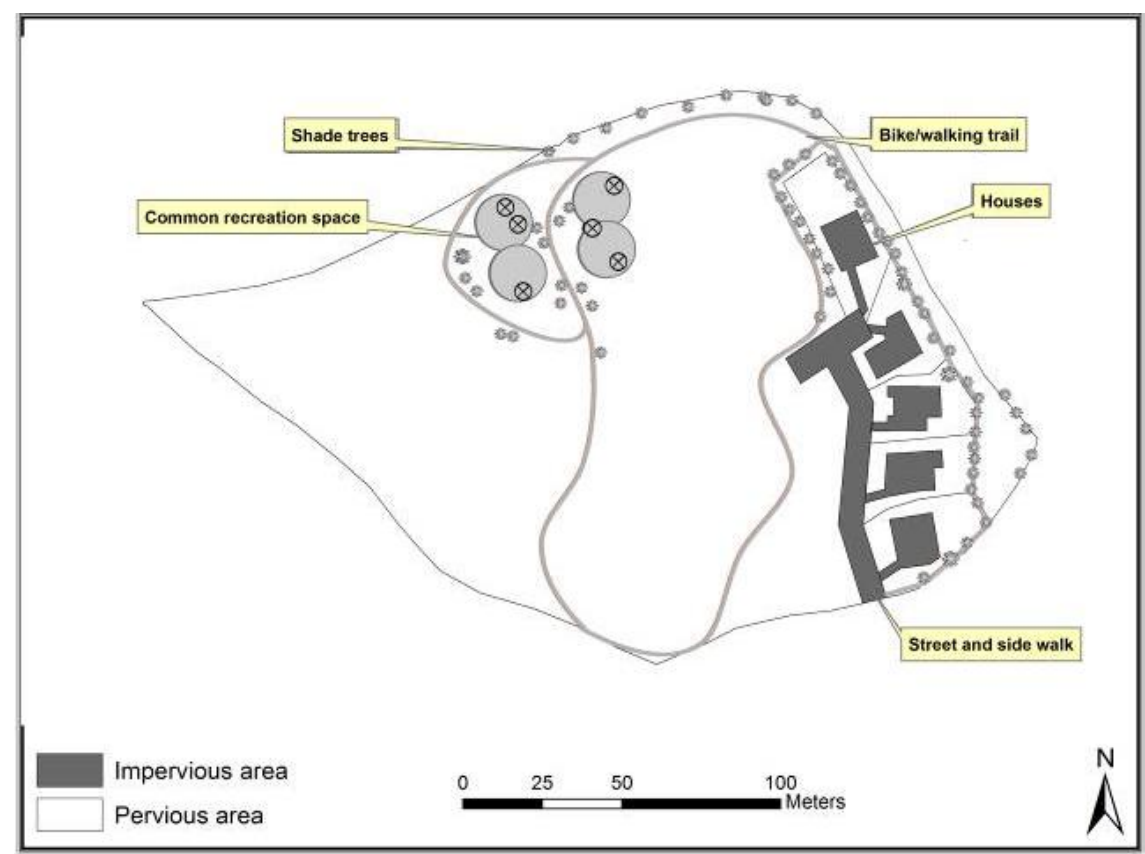

Figure 7. LSA-LID site plan 1 on Watershed 185 at the NAEW (smaller building size).

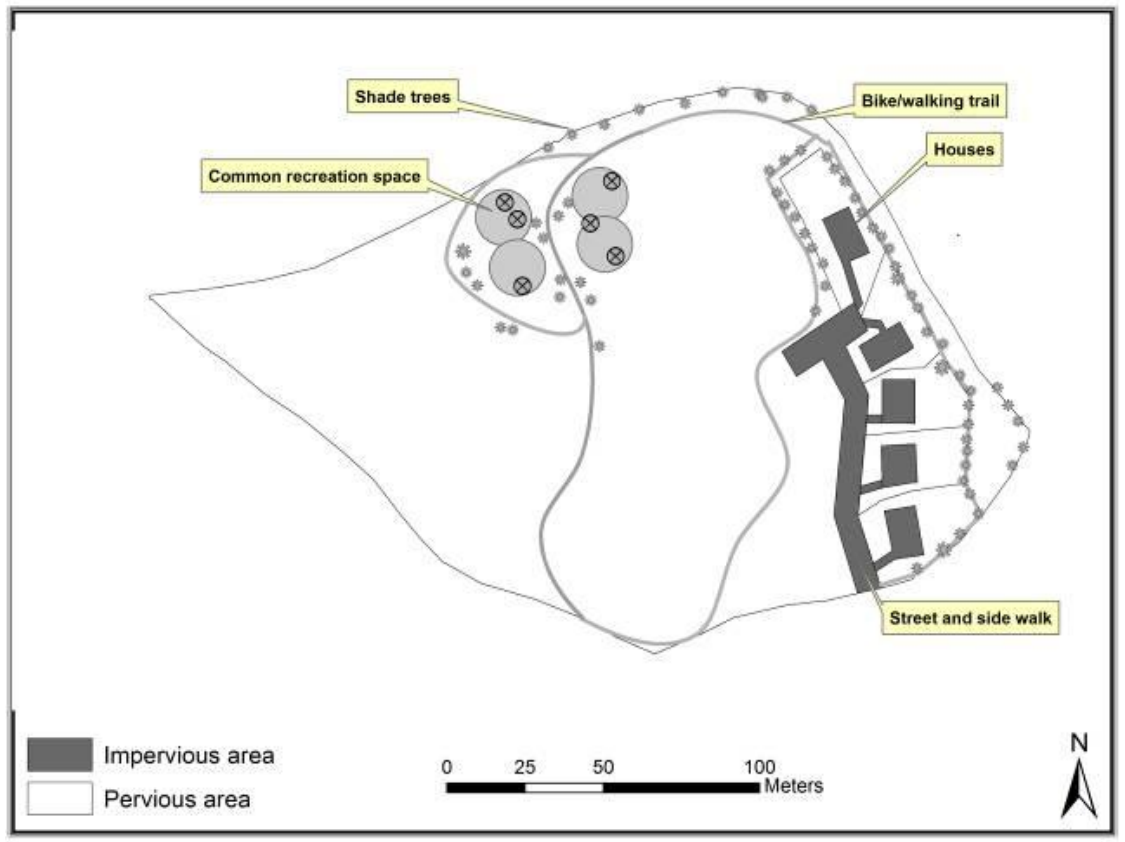

The lot sizes are reduced to help in preserving open space for common use and promote more interaction among neighbors. Because lots are smaller in size, front setbacks are reduced and houses can be closer to the access road. This helps to decrease length of driveway and increase backyard space. Reducing front yard length does not diminish the quality of design because backyards are used more often for family recreation than front yards.

A part of the common space in the LSA-LID scenarios is designed as a small picnic ground/park where slopes are relatively flatter. This space can be used to organize activities or for just casual sitting 
and recreation. Many people do in fact take advantage of opportunities to walk around a neighborhood when that choice exists [26]. Hence, a walking/biking trail is provided in the LSA-LID plan scenarios, thereby providing a contiguous path connecting various recreational features such as common space, access road, houses, etc.

Rooftop runoff in the LSA-LID scenarios is disconnected from the watershed outlet, and allowed to flow out onto lawn areas for subsequent infiltration onto areas protected against erosion. A community septic system is located behind the residential areas and serves a dual-purpose as a village green.

\subsection{Hydrological Comparison between Scenarios}

Runoff depth for each design storm increased from the pre-developed condition to either the conventional and LSA-LID development scenarios (Table 3). For the same rainfall frequencies, the increase in runoff depth for the conventional development is appreciably more than that predicted for development under LSA-LID scenarios. Compared with the pre-development (natural) condition, conventional development increased runoff depth for a 2-year storm (a typical US design standard for municipal stormwater infrastructure) by 55 percent. Similar to the projections of calibrated of pre- and post-development rainfall-runoff models presented by Booth and Jackson, runoff depth that would be expected to occur on average every 25 years under natural conditions, would occur on average every 10 years after conventional development [30].

In the conventional development scenario, failure to conserve the highly-permeable areas in the central toe slope area of the watershed, lack of sufficient detention at the parcel level, and a predominance of directly-connected impervious surface to the outlet would lead to the large increase in runoff depth. Higher runoff depths imply an increased risk of erosion and subsequent channel incision, increasing the amount of sediment transported and deposited to downstream locations.

The increases in runoff depth were less with the LSA-LID development scenarios than those from conventional development due to a reduction in land disturbance and conservation of areas better suited for infiltration and detention of storm runoff. For the 2-year recurrence interval storm, runoff depth increases under the LSA-LID development plans are only 26 percent greater than with the same building size (LSA-LID 1) and only 17 percent with the reduced building size (LSA-LID 2). The conservation of the more infiltrative and better drained soils on the west side and near the outlet of the watershed with a concomitant minimization and centralization of impervious area are the predominant factors explaining this outcome. The outcome of the suitability analysis suggested positioning impervious surfaces in such a way that slope and soil factors contributing to the abstraction or infiltration of precipitation led to smaller quantities of runoff than estimated for conventional development. The smaller impervious area in the LSA-LID scenario that was designated for buildings and roads (compared with conventional development which had no limitations) led to denser development in part of the site and retained greater amounts of open-space, which may enhance opportunities for abstraction and infiltration along longer runoff flow paths. LSA-LID management is meant to capture the smaller storm depths that make up the vast majority of total annual rainfall, as opposed to handling runoff from infrequent larger flooding rainfall events. The anticipated decline in LSA-LID effectiveness for larger storm events is borne out in our results (Table 3) as the percent 
increase in runoff depth due to either LSA-LID development scenario decreased and leveled out for storms above the 10-year recurrence interval.

Table 3. Comparison of runoff depths and percentage increases for different scenarios.

\begin{tabular}{|c|c|c|c|c|c|}
\hline \multicolumn{6}{|c|}{ Runoff Depth Using Equation $2(\mathrm{~cm})$} \\
\hline $\begin{array}{l}\text { Recurrence } \\
\text { Interval } \\
\text { (Year) } \\
\end{array}$ & $\begin{array}{l}\text { Rainfall } \\
\text { Depth } \\
(\mathrm{cm})\end{array}$ & Existing & Conventional & $\begin{array}{c}\text { LSA-LID 1 } \\
\text { w/large building } \\
\text { size } \\
\end{array}$ & $\begin{array}{l}\text { LSA-LID } 2 \mathrm{w} / \mathrm{small} \\
\text { building size }\end{array}$ \\
\hline 2 & 6.4 & 1.1 & 1.7 & 1.3 & 1.2 \\
\hline 10 & 8.9 & 2.4 & 3.3 & 2.8 & 2.7 \\
\hline 25 & 10.2 & 3.2 & 4.2 & 3.7 & 3.5 \\
\hline 50 & 11.4 & 4.1 & 5.2 & 4.6 & 4.4 \\
\hline 100 & 12.7 & 5.0 & 6.2 & 5.6 & 5.4 \\
\hline \multicolumn{6}{|c|}{ Runoff Depth (\% increase from natural) } \\
\hline $\begin{array}{l}\text { Recurrence } \\
\text { Interval } \\
\text { (Year) } \\
\end{array}$ & $\begin{array}{l}\text { Rainfall } \\
\text { Depth } \\
(\mathrm{cm})\end{array}$ & Existing & Conventional & $\begin{array}{c}\text { LSA-LID } 1 \\
\text { w/large building } \\
\text { size } \\
\end{array}$ & $\begin{array}{c}\text { LSA-LID } 2 \\
\text { w/smaller dwelling } \\
\text { area } \\
\end{array}$ \\
\hline 2 & 6.4 & $\mathrm{n} / \mathrm{a}$ & $55 \%$ & $26 \%$ & $17 \%$ \\
\hline 10 & 8.9 & $\mathrm{n} / \mathrm{a}$ & $37 \%$ & $18 \%$ & $12 \%$ \\
\hline 25 & 10.2 & $\mathrm{n} / \mathrm{a}$ & $31 \%$ & $15 \%$ & $9 \%$ \\
\hline 50 & 11.4 & $\mathrm{n} / \mathrm{a}$ & $28 \%$ & $14 \%$ & $9 \%$ \\
\hline 100 & 12.7 & $\mathrm{n} / \mathrm{a}$ & $25 \%$ & $12 \%$ & $8 \%$ \\
\hline
\end{tabular}

\section{Conclusions}

In the present study we have applied a few facets of LID in a planning context especially as it relates to conservation design, minimize development impacts on sensitive or unique areas, maintain or improve on natural timing of water flows through the watershed. Regardless of the sizes of dwellings and imperviousness, a straightforward, comparative hydrologic analysis of low-impact development plans can be obtained from land-suitability analysis based on important watershed hydrological characteristics. The study supports our assertion that detailed site physiographic data can improve on conventional site-development practice. An order-1 soil survey was foundational in the identification of regions with high carrying capacity for runoff and drainage; this was accomplished without long-term pre-development monitoring of hydrology at the site. Yet, without actually implementing and monitoring such a development, our results stand as modeled approximations of what runoff response from the development plans. While a detailed survey may not be within the purview or budget of developers, we advocate its use in situations where soil variability is high and soil data quality is low; and the site has heterogeneity in slope. Cost information is limited to the experience of the primary author in commissioning NRCS to perform an order-1 survey on a $2 \mathrm{~km}^{2}$ area in suburban Cincinnati $\mathrm{OH}$ at a cost of (US) $\$ 12,000$. Since indigenous knowledge of soils is generally limited to scientists and agricultural producers, and not passed on to or taken up by developers, an improvement of planning and development practice calls for some additional integrative research as a joint effort by the soils and planning communities. 
While GIS based software can be used effectively to perform suitability analysis, use of decision support software like CommunityViz makes it easier to carry out the analysis and display results in visually attractive form with minimum effort. Since this software provides more dynamic, interactive and user friendly tools for analysis it has the potential to attract more users especially planners, developers and policy makers.

While economics of the LSA-LID were not investigated, the present study suggests some potential cost savings. The allocation of development features to parcels impacted least can be an important way to reduce the hydrological impacts of development without costly investment in structural controls (e.g., retention basins) that require large capital investment, commitment of larger tracts of land for their construction, and subsequent maintenance costs. Savings can also potentially be realized by reduction in stormwater infrastructure to convey water from the site. Furthermore, costs associated with compliance with water-quality regulations can be reduced because of the decrease in runoff and expected erosion. These costs are offset to some degree by potentially increased costs for detailed site characterization to quantify the inputs required by the land suitability analysis.

The present study is a promising example of how site factors can be incorporated into a simple development-planning tool. Other factors could be incorporated and other response variables evaluated such as peak runoff rate and water-quality constituents.

\section{Acknowledgements}

The authors recognize the efforts and experience of Ed Redmond (USDA NRCS, retired) for conducting the soil survey that was foundational to this work.

\section{References and Notes}

1. Kaiser, E.J.; Godschalk, D.R.; Chapin, F.S., Jr. Urban Land Use Planning; University of Illinois Press: Urbana, IL, USA, 1995.

2. McHarg, I.L. Design with Nature; Nature History Press: New York, NY, USA, 1969.

3. Conine, A.; Xiang, W.; Young, J.; Whitley, D. Planning for multi-purpose greenways in Concord, North Carolina. Landscape Urban Plan. 2004, 68, 271-287.

4. Ahern, J. Green Infrastructure for Cities: The Spatial Dimension. In Cities of the Future towards Sustainable Water and Landscape Management; Novotny, V., Brown, P., Eds.; IWA Publishing: London, UK, 2007.

5. Dietz, M.E. Low impact development practices: A review of current research and recommendations for future directions. Water Air Soil Pollut. 2007, 186, 351-363.

6. Johnson, C.W. Planning and designing for the multiple use role of habitats in urban/suburban landscapes in the Great Basin. Landscape Urban Plan. 1995, 32, 219-225.

7. Tourbier, T. Open space through stormwater management: Helping to structure growth on the urban fringe. J. Soil Water Conserv. 1994, 49, 14-21.

8. McGuckin, C.P.; Brown, R.D. A landscape ecological model for wildlife enhancement of stormwater management practices in urban greenways. Landscape Urban Plan. 1995, 33, 227-246.

9. Naef, F.; Scherrer, S.; Weiler, M. A process based assessment of the potential to reduce flood runoff by land use change. J. Hydrol. 2002, 267, 74-79. 
10. Arendt, R. Linked landscapes: Creating greenway corridors through conservation subdivision design strategies in the northeastern and central United States. Landscape Urban Plan. 2004, 68, 241-269.

11. Arendt, R. Growing Greener: Putting Conservation into Local Plans and Ordinances; Island Press: Washington, DC, USA, 1999.

12. Felson, A.J.; Pickett, S.T.A. Designed experiments: New approaches to studying urban ecosystems. Front. Ecol. Environ. 2005, 3, 549-556.

13. U.S. General Soil Map (STATSGO2) for [State]; Soil Survey Staff, Natural Resources Conservation Service, U.S. Department of Agriculture: Washington, DC, USA, 2006; Available online: http://soildatamart.nrcs.usda.gov (accessed on 13 June 2010).

14. National Soil Survey Handbook, Title 430-VI; Natural Resources Conservation Service, U.S. Department of Agriculture: Washington, DC, USA, 2007.

15. Urban Hydrology for Small Watersheds: TR-55; Natural Resources Conservation Service, U.S. Department of Agriculture: Washington, DC, USA, 1986.

16. Hawkins, R.H.; Ward, T.J.; Woodward, D.E.; Van Mullem, J.A. Curve Number Hydrology: State of the Practice; American Society of Civil Engineers: Reston, VA, USA, 2010.

17. Huang, M.; Gallichand, J.; Dong, C.; Wang, Z.; Shao, M. Use of soil moisture data and curve number method for estimating runoff in the Loess Plateau of China. Hydrol. Process. 2007, 21, 1471-1481.

18. Kim, N.W.; Lee, J. Temporally weighted average curve number method for daily runoff simulation. Hydrol. Process. 2008, 22, 4936-4948.

19. Kottegoda, N.T.; Natale, L.; Raiteri, E. Statistical modelling of daily streamflows using rainfall input and curve number technique. J. Hydrol. 2000, 234, 170-186.

20. Muzik, I. A physically based method for prediction of runoff frequencies. Environ. Monit. Assess. 1992, 23, 129-135.

21. Zhan, X.; Huang, M. ArcCN-Runoff: An ArcGIS tool for generating curve number and runoff maps. Environ. Model. Softw. 2004, 19, 875-879.

22. Kelley, G.E.; Edwards, W.M.; Harrold, L.L.; McGuinness, J.L. Soils of the North Appalachian Experimental Watershed; USDA Miscellaneous Publication No. 1296; U.S. Government Print Office: Washington, DC, USA, 1975.

23. Wang, X.; Yu, S.; Huang, G.H. Land allocation based on integrated GIS-optimization modeling at a watershed level. Landscape Urban Plan. 2004, 66, 61-74.

24. Time-Saver Standards for Housing and Residential Development, 2nd ed.; De Chiara, J., Panero, J., Zelnik, M., Eds.; McGraw-Hill: New York, NY, USA, 1995.

25. Arendt, R. Conservation Design for Subdivisions; Island Press: Washington, DC, USA, 1996.

26. Arendt, R. Rural by Design: Maintaining Small Town Character; Planners Press: Washington, DC, USA, 1994.

27. Huff, F.A.; Angel, J.R. Rainfall Frequency Atlas of the Midwest; Bulletin 71; Illinois State Water Survey: Champaign, IL, USA, 1992.

28. Hempel, J.W.; Graham, T.E. Soil Survey of Coshocton County, Ohio; U.S. Department of Agriculture: Washington, DC, USA, 1991. 
29. Syme, G.J.; Fenton, D.M.; Coakes, S. Lot size, garden satisfaction and local park and wetland visitation. Landscape Urban Plan. 2001, 56, 161-170.

30. Booth, D.B.; Jackson, C.R. Urbanization of aquatics-Degradation thresholds, stormwater detention, and limits of mitigation. J. Am. Water Resour. As. 1997, 33, 1077-1090.

(C) 2010 by the authors; licensee MDPI, Basel, Switzerland. This article is an Open Access article distributed under the terms and conditions of the Creative Commons Attribution license (http://creativecommons.org/licenses/by/3.0/). 